\title{
Insight Into Electrothermal Atomization Mechanism of Several Transition Metals (Cr, Cu, Mn, Ni, Zn) in Uranium and Thorium Matrices: GFAAS Study
}

\author{
Santosh Kumar Gupta*, S.K. Thulasidas, P.J. Purohit, Neelam Goyal, and S.V. Godbole \\ Radiochemistry Division, Bhabha Atomic Research Centre \\ Trombay, Mumbai, 400085, India
}

\section{INTRODUCTION}

Atomic absorption spectrometry utilizing an electrically heated graphite furnace as the atomization device has proven to be a very successful method for the direct determination of a number of important trace elements in nuclear materialbased samples (1-6). This advantage could become universal only if the chemical interferences that occur for some elements could be nullified. These studies showed that the absorbance signal observed for all of the analytes in pure uranium (U) (7-11) thorium (Th) $(5,12)$ or mixed uranium + thorium matrices $(2,4,13)$ was suppressed compared to that observed for pure matrixfree solutions. This necessitates a complete understanding of the atom formation mechanism with and without the matrices and also the factors influencing this process. In addition to the suppression in the magnitude of the analyte signal and the changes in the useful analytical life of the graphite furnace, surface studies were also taken up to understand the changes occurring in the surface composition and morphology of the atomizer.

In view of the importance of uranium and thorium, work has been carried out on the atom formation of $\mathrm{Cr}, \mathrm{Cu}, \mathrm{Mn}, \mathrm{Ni}$, and $\mathrm{Zn}$ in aqueous, uranium, and thorium matrices. The quality control of uraniumand thorium-based nuclear materials is essential as uranium is used as a nuclear fuel in Pressurized Heavy Water Reactors (PHWRs), thorium

\footnotetext{
*Corresponding autbor.

E-mail: santoshg@barc.gov.in
}

\section{ABSTRACT}

To understand the reason behind the suppression of analyte absorbance in the presence of uranium and thorium matrices, studies were taken up to understand the reaction mechanism for $\mathrm{Cr}, \mathrm{Cu}, \mathrm{Mn}, \mathrm{Ni}$, and $\mathrm{Zn}$ analytes with and without matrices. Reaction mechanisms were proposed for atom formation using Arrhenius plots. Investigations reveal that the activation energies for these analytes in uranyl and thorium nitrate solutions are similar to those obtained in pure aqueous solutions and, hence, similarity in the atomization mode for all of these elements. With a view to understanding the suppressive effect due to the matrix, investigations were carried out using scanning electron microscopy (SEM) on the products formed on atomization for $\mathrm{Cr}, \mathrm{Cu}, \mathrm{Mn}, \mathrm{Ni}$, and $\mathrm{Zn}$ in aqueous, uranium, and thorium matrices. The investigations reveal that uranium and thorium matrices react with the graphite atomizer surface, leading to the formation of an uneven surface which affects the atomization efficiency, while an aqueous solution does not create any defect on the surface.

is used as a blanket material in Fast Breeder Reactors (FBR), and U+Th is the proposed fuel for Advanced Heavy Water Reactors (AHWR) (14).

India has vast reserves of thorium (Th) and the three-stage Indian nuclear program is based on the utilization of thorium for pro- duction of fissile ${ }^{233} \mathrm{U}$ in the Fast Breeder Reactor (FBR) and use of $\left(\mathrm{Th}-\mathrm{U}^{233}\right) \mathrm{O}_{2}$ as a fuel in the Advanced Heavy Water Reactor (AHWR). Hence, trace metal characterization of Th becomes an essential feature for its use as a nuclear material. Past studies were carried out for the development of GFAAS-based methods for the determination of $\mathrm{Cr}, \mathrm{Cu}, \mathrm{Mn}, \mathrm{Ni}$, and $\mathrm{Zn}$ in a Th matrix using small sample sizes without chemically separating the matrix. Likewise, quality control of $U$ and $U+T h$ is carried out for use with Pressurized Heavy Water Reactors (PHWR) and the proposed fuel for Advanced Heavy Water Reactors (AHWR). The studies include investigation of the effects on analyte absorbance due to the presence of the matrices, its concentration, and accumulation inside the graphite furnace atomizer. Elements such as $\mathrm{Cr}$, Ni, etc. are generally monitored to check for process pick-up and the conditions of the process equipment. The presence of $\mathrm{Ni}$ in high concentrations also leads to problems in sintering. Low melting elements such as zinc, if present, will cause liquid metal embrittlement altering the fuel structure and causing failure. The presence of $\mathrm{Cu}, \mathrm{Mn}$, and $\mathrm{Zn}$ is monitored to ensure the total impurity content mentioned within the specified limit and also to ensure the individual impurity content under specified limits. In general, the presence of light elements results in a change in density and reduction in fissile content. It is, therefore, necessary to characterize nuclear materials for trace metallic constituents as part of their chemical quality control (CQC). 
The electrothermal atomization mode in atomic absorption spectrometry (ETA-AAS) displays high atomization efficiency on several counts, such as efficient sample introduction, compact size of atomizer, and fairly uniform higher temperature as compared to flame systems. The electrothermal atomization mode, however, makes complete description of the atom formation mechanism more difficult due to an increase in the number of interfering species, which are chemical in nature. The studies on atomization processes reported in the literature (15-19) are all carried out on analytes with water or weak acids with a zirconium matrix (6). However, the reaction mechanism on the basis of activation energies $\left(\mathrm{E}_{\mathrm{a}}\right)$ calculation using Arrhenius plots is not yet reported for $\mathrm{Cr}$, $\mathrm{Mn}, \mathrm{Ni}, \mathrm{Cu}$, and $\mathrm{Zn}$ in uranium and thorium matrices using the GFAAS technique. The nature of the reaction mechanism in the presence of matrices such as $U$ and Th gets altered because of various interactions taking place in the graphite atomizer viz. analyte-carbon, analyte-matrix and carbon-matrix. These interactions are bound to influence the atomization process to varying degrees, which in turn affect the analytical results.

The aim of the present study is to understand the reason for the change in the analyte absorbance signals with a change in matrix on the basis of the mode of atomization and the possible intermediate reaction sequence. These studies give an insight into the relation between the atoms formed and their precursors during atomization. It is well documented that analyte absorbance reduces in the presence of these matrices $(1,4,6)$. The basic atomization mechanism involved in these studies, for some of the analytes, appears to be through carbothermic reduction and, for some, through oxide dissociation prior to atomization.

\section{EXPERIMENTAL}

\section{Instrumentation}

To study the atomization mechanism in $\mathrm{U}$ and Th matrices, a computer-controlled GBC-906 atomic absorption spectrometer, equipped with a GF 3000 graphite furnace atomizer (GBC Scientific Equipment Pvt., Ltd., Australia), was used. The details of the instrument are provided in Table I and reported earlier in detail (1).

The atomizer was covered with a shield consisting of a Perspex ${ }^{\circledR}$ sheet which could be removed when access to the atomizer was necessary. Containment of uranium and thorium fumes was ensured through the adequate exhaust system provided around the atomizer. The atomizer unit exhaust was connected to a glove box exhaust system (see Figure 1).

TABLE I

Instrumental Parameters

\begin{tabular}{lr}
\hline Instrumentation & GBC-906 AAS \\
Graphite furnace & GF $3000 \mathrm{GFA}$ \\
Spectral bandwidth & $0.5 \mathrm{~nm}$ \\
Lamp fill gas & $\mathrm{Ne}$ \\
Gas used & $\mathrm{Ar}$ \\
Flow rate & $6 \mathrm{~L} / \mathrm{min}$ \\
Lamp current & $15 \mathrm{~mA}$ \\
\hline
\end{tabular}

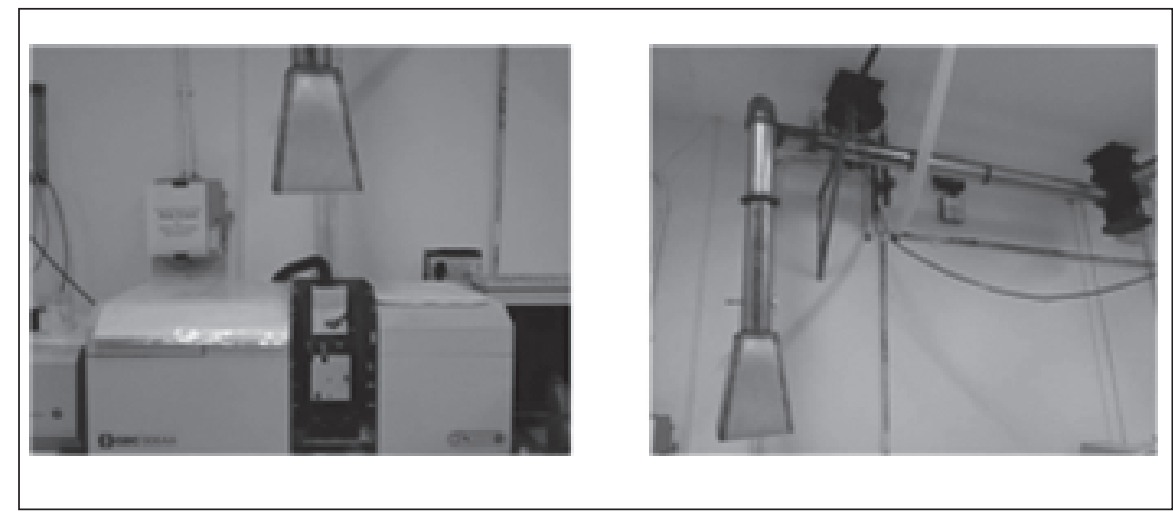

Fig.1. Schematic of atomizer with glove box exhaust system.
The morphological investigations of the products formed on the graphite atomizer surface were carried out using a scanning electron microscope (SEM). This was done on an instrument having both an Everhart-Thornley, UK, secondary electron detector and a solid state back-scattered electron detector. The micrographs were taken at 20-30 kV acceleration voltages.

\section{Standard Solutions and Reagents}

Details of the sample preparation are given earlier (6) for the uranium $(200 \mathrm{mg} / \mathrm{mL})$ and thorium (200 mg/mL) solutions. Analyte solutions were prepared by appropriate dilution of the standard stock solutions (Cr, $\mathrm{Cu}, \mathrm{Mn}, \mathrm{Ni}$, and $\mathrm{Zn}$ ) of $1 \mathrm{mg} / \mathrm{mL}$ in $5 \%$ nitric acid (VHG Labs., Manchester, NH, USA). The instrumental parameters used for these analytes are reported elsewhere (5). Argon gas of 99.995\% purity was used as the purge gas.

The following experiments were carried out for all of the analytes using a programmable heating cycle and a computerized signal recording system. Absorbance-time and temperature-time profiles were obtained simultaneously as a computer output. 


\section{Effect of Matrix on Signal Appearance Temperature $\left(\mathbf{T}_{\text {app }}\right)$}

The profiles were obtained using different temperature settings on the GF-3000 control unit. From the initial portion of the profile at various temperature points, corresponding absorbance signals were measured at a fixed analyte concentration. The lowest temperature, where a detectable signal was obtained above the blank signal, was taken as the appearance temperature $\left(\mathrm{T}_{\mathrm{app}}\right)(16)$ in the aqueous, uranium, and thorium matrices.

\section{Determination of Activation Energies for Atom Formation}

For a fixed concentration of the analyte, the atomization temperature was measured from $\mathrm{T}_{\mathrm{app}}$ onwards. The corresponding absorbance signals were measured for different temperatures, and a plot of logarithm of the absorbance as a function of the inverse of the absolute temperature was obtained. It should normally yield a straight line with the slope of an Arrhenius plot giving the activation energy. The free atoms in the gaseous state are formed either through oxide dissociation or carbothermic reduction of the oxides (if Gibbs' free energy change is negative at $\mathrm{T}_{\mathrm{app}}$ ) (18). Hence, with a free energy change, the melting/boiling points of analyte/analyte oxides are the guidelines for understanding the basic reaction mechanism. The procedure was repeated for all of the analytes in the aqueous as well as the uranium and thorium matrices.

\section{Temperature Measurements in the GBC-906 GF 3000}

In the GBC-906 GF 3000 unit, the temperatures are set for any absorbance measurement and are not monitored during measurements, so the actual temperatures are not known. In activation energy calculations, an error in temperature can lead to erroneous results for the atomization mechanism.
Keeping this in view, temperature measurement studies were carried out in the range of $1000-3000{ }^{\circ} \mathrm{C}$. The temperatures were set on the instrument using programmable heating parameters and measured using a Model M/s Raytek two-color optical pyrometer (Raytek Inc., USA), sensitive in the range of $1000-3000{ }^{\circ} \mathrm{C}$, and providing a fast response. There was exceptionally good agreement between the set and measured temperatures in the $1000-2800{ }^{\circ} \mathrm{C}$ range. However, beyond $2800{ }^{\circ} \mathrm{C}$, there was a $\pm 100{ }^{\circ} \mathrm{C}$ error in the measured temperature. These temperatures were used in the $\mathrm{E}_{\mathrm{a}}$ calculations and for studying the reaction mechanism. The activation energies and $\mathrm{T}_{\text {app }}$ were, in turn, compared with those reported in the literature to infer the final mode of atomization.

\section{Scanning Electron Microscope Experiments}

For surface studies, graphite atomizers were treated with the matrix heated to $2700{ }^{\circ} \mathrm{C}$ for 40 atomization cycles. Separate atomizers for each of the matrices were prepared by loading $5 \mu \mathrm{L}$ of (a) $0.1 \mathrm{M} \mathrm{HNO}_{3}$, (b) uranyl nitrate (20 $\mathrm{mg} / \mathrm{mL})$, (c) thorium nitrate
(20 mg/mL), and (d) 300 atomization cycles with $0.1 \mathrm{M} \mathrm{HNO}_{3}$. Surface erosion was studied using SEM on the residue collected after heating the atomizer with the solutions.

\section{RESULTS AND DISCUSSION}

In order to understand the factors responsible for suppression in the absorbance signal, the atomization mechanism was investigated for all of the analytes with and without matrices. The atomization mechanism was studied using the thermodynamic approach as published by Sturgeon et al. (20). From the initial portion of the timeabsorbance profile (Figure 2), the Arrhenius plots were generated and the $\mathrm{T}_{\text {app }}$ and activation energies obtained for the atomization process involved. Since construction of a $\log$ Absorbance versus 1/T plot requires that the temperature of the atomic vapor be equal to that of the surface of the furnace, absorbance measurements for the $\mathrm{E}_{\mathrm{a}}$ value calculations were restricted to the initial few hundred milliseconds of the absorption profile (Figure 2, absorbance-time profile). Absorbance data taken from this region of the curve were used to construct the Arrhenius plots. The

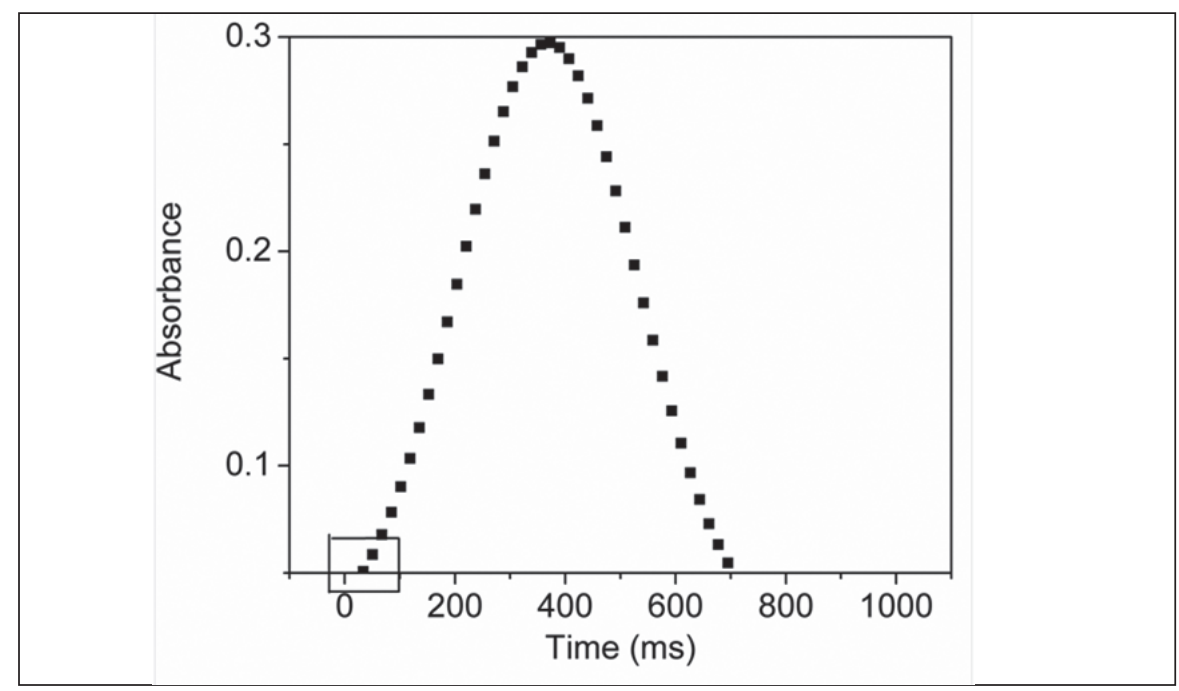

Fig. 2. Typical absorbance-time profile showing the part of the curve from which the data were taken for chromium. 
$\mathrm{T}_{\text {app }}$ obtained for all of the analytes in the presence of the three matrices along with the $\mathrm{E}_{\mathrm{a}}$ values obtained are listed in Table II.

The $\mathrm{T}_{\text {app }}$ for $\mathrm{Cr}$ did not change much with the matrix, while for $\mathrm{Cu}, \mathrm{Mn}, \mathrm{Ni}$, and $\mathrm{Zn}$ the changes observed were high. For the oxides to undergo carbothermic reduction, the free energy change per mole $\left(\Delta G^{\circ}\right)$ should be negative at $T_{\text {app }}$. It was observed that the standard free energy change per mole $\left(\Delta G^{\circ}\right)$ does not become negative at $\mathrm{T}_{\mathrm{app}}$ for $\mathrm{Mn}$ and $\mathrm{Zn}$, and hence, the carbothermic reduction does not become a thermodynamically favorable reaction. However, for $\mathrm{Cr}, \mathrm{Cu}$, and $\mathrm{Ni}$ the standard free energy change per mole $\left(\Delta G^{\circ}\right)$ becomes negative at $\mathrm{T}_{\mathrm{app}}$, and hence, the carbothermic reduction becomes a thermodynamically favorable reaction.

Activation energy corresponding to a single slope or two slopes was obtained. Single slope, determined for $\mathrm{Mn}$ and $\mathrm{Zn}$, corresponds to single activation energy value, whereas two slopes were obtained for $\mathrm{Cr}$, $\mathrm{Cu}$, and $\mathrm{Ni}$ corresponding to two activation energy values. The activation energies and $\mathrm{T}_{\text {app }}$ were compared with those reported in the literature (21-23) to infer about the final mode of atomization. Two major pathways leading to gaseousfree atoms were identified: reduction of the analyte oxide by carbon or thermal dissociation of the metal oxide with subsequent sublimation/ vaporization of the metal. The specific details of the atomization mechanism for each of the analytes in the presence and absence of matrices are discussed below.

\section{Chromium}

Chromium nitrate, $\mathrm{Cr}\left(\mathrm{NO}_{3}\right)_{3}$, heated under carbon rod atomizer (CRA) conditions, produces $\mathrm{Cr}_{2} \mathrm{O}_{3}$. The appearance temperature obtained for $\mathrm{Cr}$ in nitrate solution is $1960 \mathrm{~K}$. It is known that $\mathrm{Cr}_{2} \mathrm{O}_{3}$ is the most stable oxide of $\mathrm{Cr}$ at $1960 \mathrm{~K}(21)$ since the melting point of $\mathrm{Cr}_{2} \mathrm{O}_{3}$ is $2700 \mathrm{~K}$. The free energy change for the carbothermic reduction process of $\mathrm{Cr}_{2} \mathrm{O}_{3}$ is negative at $\mathrm{T}_{\text {app }}$; hence, it is possible that $\mathrm{Cr}_{2} \mathrm{O}_{3}$ undergoes carbothermic reduction prior to its atomization. The reduction of the oxide by carbon at $\mathrm{T}_{\mathrm{app}}$ is also given in the literature (20) as:

Eq. 1
$\mathrm{Cr}_{2} \mathrm{O}_{3(\mathrm{~s})}+3 \mathrm{C}_{(\mathrm{s})} \rightarrow 2 \mathrm{Cr}_{(\mathrm{s} / \mathrm{l})}+3 \mathrm{CO}_{(\mathrm{g})}$

TABLE II

$E_{a}$ Values Obtained With the Appearance Temperatures With and Without $U$ and Th Matrices

\begin{tabular}{cccc|ccc}
\hline Element & \multicolumn{3}{c}{$\mathrm{T}_{\text {app }} \mathrm{K}$} & \multicolumn{3}{c}{$\mathrm{E}_{\mathrm{a}}(\mathrm{kcal} / \mathrm{mole})$} \\
& Aqu. & $\mathrm{U}$ & $\mathrm{Th}$ & Aqu. & $\mathrm{U}$ & $\mathrm{Th}$ \\
\hline $\mathrm{Cr}$ & $1960 / 1660^{\mathrm{a}}$ & 2030 & 2030 & $98 \pm 4^{\mathrm{b}}$ & $94 \pm 5^{\mathrm{b}}$ & $98 \pm 3^{\mathrm{b}}$ \\
& & & & $45 \pm 5^{\mathrm{c}}$ & $50 \pm 6^{\mathrm{c}}$ & $54 \pm 6^{\mathrm{c}}$ \\
$\mathrm{Cu}$ & $1200 / 1270^{\mathrm{a}}$ & 1400 & 1400 & $80 \pm 4^{\mathrm{b}}$ & $78 \pm 3^{\mathrm{b}}$ & $79 \pm 4^{\mathrm{b}}$ \\
& & & & $46 \pm 2^{\mathrm{c}}$ & $44 \pm 2^{\mathrm{c}}$ & $40 \pm 4^{\mathrm{c}}$ \\
$\mathrm{Mn}$ & $1480 / 1480^{\mathrm{a}}$ & 1800 & 1800 & $97 \pm 4$ & $93 \pm 4$ & $104 \pm 6$ \\
$\mathrm{Ni}$ & $1700 / 1590^{\mathrm{a}}$ & 1900 & 1900 & $99 \pm 5^{\mathrm{b}}$ & $101 \pm 8^{\mathrm{b}}$ & $97 \pm 5^{\mathrm{b}}$ \\
& & & & $46 \pm 3^{\mathrm{c}}$ & $53 \pm 3^{\mathrm{c}}$ & $45 \pm 3^{\mathrm{c}}$ \\
$\mathrm{Zn}$ & $1140 / 1140^{\mathrm{a}}$ & 1340 & 1340 & $81 \pm 3$ & $83 \pm 4$ & $87 \pm 6$ \\
\hline
\end{tabular}

${ }^{\mathrm{a}}$ Reported (20), ${ }^{\mathrm{b}}$ Lower temperature, ${ }^{\mathrm{e}}$ Higher temperature.

\section{Atomic Apectroscopy 1 Vol. 34(6), Nov./Dec. 2013}

The Cr Arrhenius plot (Figure 3) shows two straight line segments with different slopes intersecting at the temperature of $2100 \mathrm{~K}$. Two sequential atomization energies were obtained for $\mathrm{Cr}$ when the analyte is taken as nitrate solution. The values corresponding to two slopes are $98 \pm 4$ and $45 \pm 5 \mathrm{kcal} / \mathrm{mole}$, respectively, for lower and higher temperatures. The $\mathrm{E}_{\mathrm{a}}$ value obtained in the lower temperature regions $(<2100 \mathrm{~K})$ is in close agreement with the heat of sublimation of $\mathrm{Cr}_{(\mathrm{s})}$ (22) and in the higher temperature regions $(>2100 \mathrm{~K}$ ) close to dissociation of the dimer (23). The reported value by Gaydon et al. (23) is $44 \mathrm{kcal} / \mathrm{mol}$. Below the $\mathrm{T}_{\mathrm{app}}$ temperature, $\mathrm{Cr}_{2} \mathrm{O}_{3}$ is the most stable oxide of $\mathrm{Cr}$ and must be in solid state. Hence, the possible pathway for chromium atom formation is given as:

Eq. 2

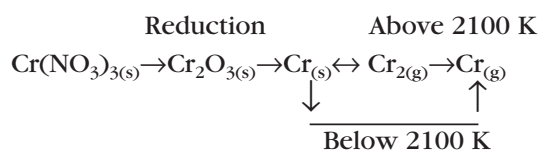

Initially, the concentration of $\mathrm{Cr}_{2(\mathrm{~g})}$ was very low and in equilibrium with the condensed phase metal. Hence, $\mathrm{Cr}_{(\mathrm{g})}$ atoms were formed by the sublimation of $\mathrm{Cr}_{(\mathrm{s})}$. With an increase in temperature, the concentration of $\mathrm{Cr}_{2(\mathrm{~g})}$ increases. At sufficiently high temperatures $(>2100 \mathrm{~K})$, the bulk of the $\mathrm{Cr}_{(\mathrm{s})}$ sublimes, and above $2100 \mathrm{~K}$, the dimer dissociation was the dominant precursor to free atoms. A single activation energy of $99 \mathrm{kcal} / \mathrm{mole}(18)$ and $94 \mathrm{kcal} / \mathrm{mole}$ (24) was reported and no dimer species were observed by them. These authors proposed a single mechanism based on the sublimation of $\mathrm{Cr}_{(\mathrm{s})}$ after the carbothermic reduction of $\mathrm{Cr}_{2} \mathrm{O}_{3(\mathrm{~s})}$. The formation of $\mathrm{Cr}_{2(\mathrm{~g})}$ and its corresponding $\mathrm{E}_{\mathrm{a}}$ value ( $45 \mathrm{kcal} / \mathrm{mole}$ ) is reported by Gaydon et al. (23). However, Castillo et al. (25) reported two activation energies of 250 and $120 \mathrm{kcal} / \mathrm{mole}$, corresponding to 
the thermal dissociation of $\mathrm{Cr}_{2} \mathrm{O}_{3(\mathrm{~s})}$ to $\mathrm{Cr}_{(\mathrm{g})}$ at low temperature, while in the higher temperature region it is a gas phase dissociation of monoxide (CrO).

The activation energies for $\mathrm{Cr}$ in uranyl and thorium nitrate solutions are similar to those obtained in pure nitrate solutions, suggesting that the mode of atomization remained the same. Therefore, the Arrhenius plot in nitrate solution (Figure 3) is for the first time published in this paper.

\section{Copper}

The Arrhenius plot (Figure 4) for the nitrate solution of $\mathrm{Cu}$ showed two straight line segments with a $\mathrm{T}_{\text {app }}$ of $1200 \mathrm{~K}$. The slopes correspond to two atomization energies of $80 \pm 4$ and $46 \pm 4 \mathrm{kcal} / \mathrm{mole}$, intersecting at the temperature of $2100 \mathrm{~K}$. The $\mathrm{E}_{\mathrm{a}}$ values correspond to the heat of sublimation of $\mathrm{Cu}_{(\mathrm{s})}$ and the $\mathrm{Cu}-\mathrm{Cu}$ bond dissociation energies. Below $\mathrm{T}_{\text {app }}, \mathrm{CuO}_{(\mathrm{s})}$ (m.p. $1600 \mathrm{~K}$ ) is formed (21) which undergoes a reductive decomposition of the oxide. It is a thermodynamically favorable reaction at $1200 \mathrm{~K}$. The $\mathrm{E}_{\mathrm{a}}$ values obtained in the lower temperature regions $(<2100 \mathrm{~K})$ are in close agreement with the heat of sublimation of $\mathrm{Cu}_{(\mathrm{s})}(81 \mathrm{kcal} / \mathrm{mol})$ (22) and in the higher temperature region $(>2100 \mathrm{~K}$ ) dissociation of dimer (46 kcal/mol) (23).

Thermal dissociation of the metal oxide was reported by L'vov et al. (26) and Aggett et al. (27) for the formation of $\mathrm{Cu}_{(\mathrm{s} / \mathrm{l})}$ while Chang et al. (28) suggested that at $T_{\text {app }}$, $\mathrm{Cu}_{(\mathrm{s} / \mathrm{l})}$ is possible both by thermal dissociation and reduction by carbon of the copper oxide. Though thermal dissociation or carbon reduction of the metal oxide may be a matter of dispute, the presence of metallic copper on the graphite surface prior to its atomization was confirmed by all researchers. They reported that the carbothermic reduction is favorable at $1200 \mathrm{~K}$ and results in the atomization of various solid copper compounds with the average values at $360 \mathrm{~kJ} / \mathrm{mol}$ $(86 \mathrm{kcal} / \mathrm{mol})$ and $180 \mathrm{~kJ} / \mathrm{mol}$ (43 kcal/mol) (18).

In the present studies, the proposed mechanism is:

$$
\begin{aligned}
& \text { Eq. } 3 \\
& \text { Above } 2100 \mathrm{~K} \\
& \mathrm{Cu}\left(\mathrm{NO}_{3}\right)_{3} \rightarrow \mathrm{CuO}_{(\mathrm{s})} \rightarrow \underset{\text { Below } 2100 \mathrm{~K}}{\downarrow} \mathrm{Cu}_{(\mathrm{s})} \rightarrow \mathrm{Cu}_{2(\mathrm{~g})} \rightarrow \mathrm{Cu}_{(\mathrm{g})}
\end{aligned}
$$

The activation energies for $\mathrm{Cu}$ in uranyl and thorium nitrate solutions remained the same as for pure nitrate solutions, which suggests that the mode of atomization also remained essentially the same. The Arrhenius plot in aqueous solution (Figure 4) is, therefore, given. However, $\mathrm{T}_{\text {app }}$ increased by $200 \mathrm{~K}$ in the presence of uranium and thorium.

\section{Manganese}

When $\mathrm{Mn}\left(\mathrm{NO}_{3}\right)_{2} \cdot 6 \mathrm{H}_{2} \mathrm{O}(\mathrm{s})$ is heated under GF atomizer conditions, $\mathrm{MnO}_{(\mathrm{s})}$ is formed. The free energy change per mole $\left(\Delta G^{\circ}\right)$ is positive $\mathrm{T}_{\mathrm{app}}$ and, hence, the reduction of $\mathrm{MnO}_{(\mathrm{s})}$ by carbon at $\mathrm{T}_{\text {app }}$ $(1480 \mathrm{~K})$ is not favorable. Below the $\mathrm{T}_{\text {app }}, \mathrm{Mn}$ exists as $\mathrm{MnO}_{(\mathrm{s})}$ on the graphite surface under the GF atomizer conditions where the melting point is reported as $1978 \mathrm{~K}$ (22). The Arrhenius plot for the atomization of Mn (Figure 5) shows a single straight line segment. The slope corresponds to the atomization energy of $97 \pm 4 \mathrm{kcal} / \mathrm{mole}$. The atomization energy of $97 \pm 4 \mathrm{kcal} / \mathrm{mole}$ obtained for $\mathrm{Mn}$ in nitrate solutions corresponds to the bond dissociation energy of $\mathrm{MnO}$. Weast (22) also reported that on heating, $\mathrm{MnO}_{(\mathrm{s})}$ is decomposed prior to its vaporization or sublimation and, hence, the formation of $\mathrm{MnO}_{(\mathrm{g})}$ at appearance temperature is completely ruled out and the dissociation energy of $\mathrm{MnO}_{(\mathrm{s})}$ is $92 \mathrm{kcal} / \mathrm{mol}$. Thus, the most probable reaction

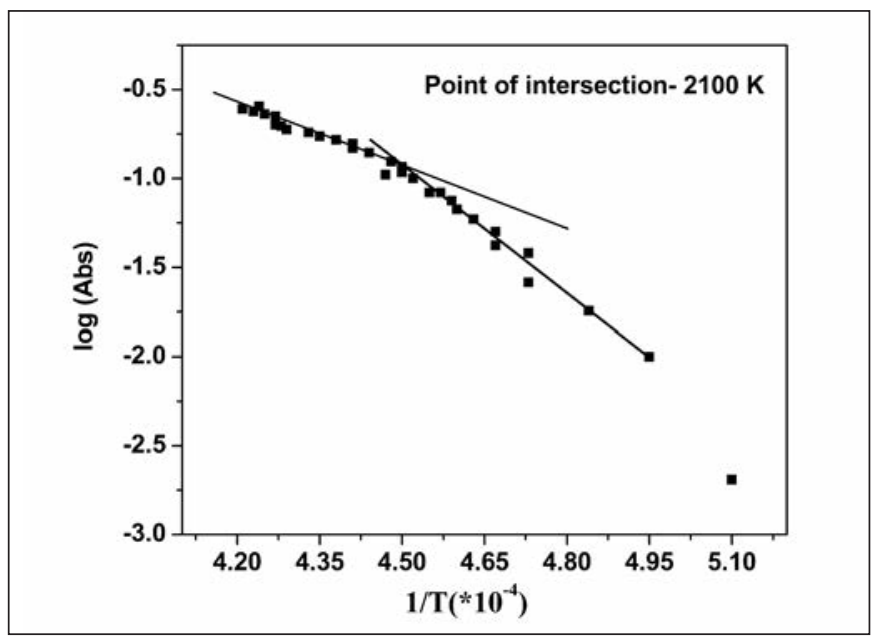

Fig. 3. Arrbenius plot for chromium in aqueous solution.

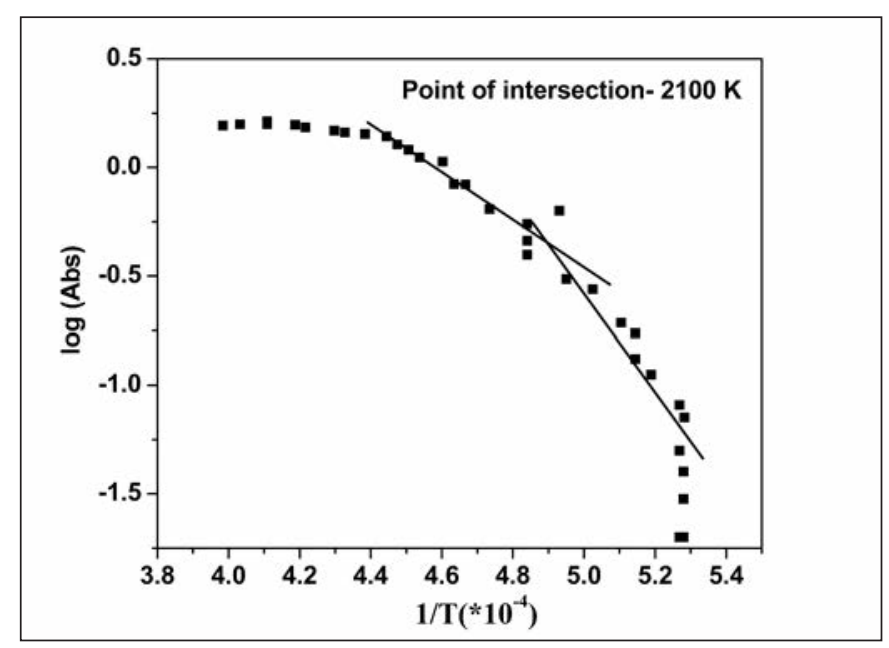

Fig. 4. Arrbenius plot for copper in aqueous solution. 


\section{Apectroscopy}

mechanism for the thermal dissociation of $\mathrm{MnO}_{(\mathrm{s})}$ is as follows:

$$
\begin{array}{ccc} 
& \multicolumn{2}{c}{\text { Eq. } 4} \\
& 575 \mathrm{~K} & 1435 \mathrm{~K} \\
\mathrm{Mn}\left(\mathrm{NO}_{3}\right)_{2} \cdot 6 \mathrm{H}_{2} \mathrm{O}(\mathrm{s}) \rightarrow \mathrm{MnO}_{(\mathrm{s})} \rightarrow \mathrm{Mn}_{(\mathrm{g})}
\end{array}
$$

It can be seen that the reduction of $\mathrm{MnO}_{(\mathrm{s})}$ by carbon at $\mathrm{T}_{\text {app }}(1480 \mathrm{~K})$ is not favorable and, hence, the carbothermic reduction of $\mathrm{MnO}_{(\mathrm{s})}$ is not possible. Chang (28) reported that $\mathrm{MnO}_{(\mathrm{s})}$ undergoes carbothermic reduction around the $T_{\text {app }}$. In contrast, the experimental results by Sturgeon et al. (18) indicated that the precursor to the atomic vapor was $\mathrm{MnO}_{(\mathrm{s})}$ and the bond dissociation energy is $390 \mathrm{~kJ} / \mathrm{mol}$ ( 93.3 kcal $/ \mathrm{mol})$. The findings in our study are supported by the results reported by Weast of $92 \mathrm{kcal} / \mathrm{mol}$, Gaydon of $96 \mathrm{kcal} / \mathrm{mol}$, and Sturgeon of $93.3 \mathrm{kcal} / \mathrm{mol}$ for the final mode of atomization.

The process leading to the atom formation of Mn appears to be affected by the uranium and thorium matrices only with an increase in $\mathrm{T}_{\text {app }}$ by approximately $200 \mathrm{~K}$ in comparison to pure nitrate solutions.

\section{Nickel}

The Arrhenius graph for atomization (Figure 6) of Ni shows two straight line segments with different slopes intersecting at a temperature of $2200 \mathrm{~K}$. Two sequential atomization energies were obtained at $99 \pm 5$ below $2200 \mathrm{~K}$ and $46 \pm 3$ $\mathrm{kcal} /$ mole above $2200 \mathrm{~K}$. The $\mathrm{T}_{\text {app }}$ for nickel is $1700 \mathrm{~K}$, less than the melting point of $\mathrm{NiO}(2263 \mathrm{~K})$. Therefore, the oxide was considered to be present in the form of solid $\mathrm{NiO}_{(\mathrm{s})}$. Gibbs' free energy change associated with the carbothermic reduction of $\mathrm{NiO}$ is negative at $\mathrm{T}_{\mathrm{app}}$. The $\mathrm{E}_{\mathrm{a}}$ values probably correspond to the heat of atomization of $\mathrm{Ni}_{(\mathrm{g})}$ and the dissociation energy of $\mathrm{Ni}_{2(\mathrm{~g})}$, respectively. To support our findings, we compared our data with the data from the literature. The formation of $\mathrm{Ni}_{2(\mathrm{~g})}$ was observed mass spectrometrically by Kant (29). Below $\mathrm{T}_{\mathrm{app}}, \mathrm{NiO}_{(\mathrm{s})}$ is formed by thermal dissociation of the nitrate (21) and is readily reduced at $T_{\text {app }}$, since the free energy change is negative for the carbothermic reduction reaction of $\mathrm{NiO}_{(\mathrm{s})}$ at $\mathrm{T}_{\text {app }}$ (30). This is likely to favor the formation of $\mathrm{Ni}_{(\mathrm{s} / \mathrm{l})}$ around the $\mathrm{T}_{\text {app }}$. Since the melting point of $\mathrm{Ni}$ is $1720 \mathrm{~K}$, Ni is present as $\mathrm{Ni}$ (see Eq. 5) on the graphite furnace. In the present studies, the energy of vaporization of $\mathrm{Ni}_{(\mathrm{I})}$ is the heat of atomization for $\mathrm{Ni}$ at lower temperatures, while the energy associated with dissociation of $\mathrm{Ni}_{2(\mathrm{~g})}$ to $\mathrm{Ni}_{(\mathrm{g})}$ atoms corresponds to higher temperatures. At low temperature, for- mation of the Ni dimer appears to be less and its concentration increases with an increase in temperature. At sufficiently high temperature, most of the $\mathrm{Ni}_{(\mathrm{I})}$ vaporizes, and beyond $2200 \mathrm{~K}$, the dimer dissociation is the precursor to $\mathrm{Ni}_{(\mathrm{g})}$ atoms. The formation of metal clusters or dimeric species of $\mathrm{Ni}$ was documented earlier (30). Thus, the most probable reaction mechanism is as follows:

$$
\begin{aligned}
& \text { Eq. } 5 \\
& \text { 613K Reductions } \\
& \mathrm{Ni}\left(\mathrm{NO}_{3}\right)_{2} \cdot 6 \mathrm{H}_{2} \mathrm{O}(\mathrm{s}) \rightarrow \mathrm{NiO}_{(\mathrm{s})} \rightarrow \mathrm{Ni}_{(\mathrm{I})} \rightarrow \\
& \text { Above 2200K } \\
& \stackrel{\mathrm{Ni}_{2(\mathrm{~g})} \rightarrow \mathrm{Ni}_{(\mathrm{g})}}{\downarrow} \\
& \text { Below 2200K }
\end{aligned}
$$

The atom formation studies carried out by various researchers suggest that there exists a number of possible pathways for the production of $\mathrm{Ni}_{(\mathrm{g})}$ atoms. Chang et al. (28) suggested that the production of $\mathrm{Ni}$ atoms through thermal decomposition and carbon reduction are spontaneous at $\mathrm{T}_{\text {app }}$ for $\mathrm{Ni}$ atoms and is also supported by L'vov (26). Brewer et al. (31) in their studies observed that the $\mathrm{Ni}_{(\mathrm{g})}$ atoms are in equilibrium with solid diatomic $\mathrm{NiO}_{(\mathrm{s})}$ at $\mathrm{T}_{\text {app }}$. However, the energy required for this reaction is significantly higher than the values obtained in the present studies.

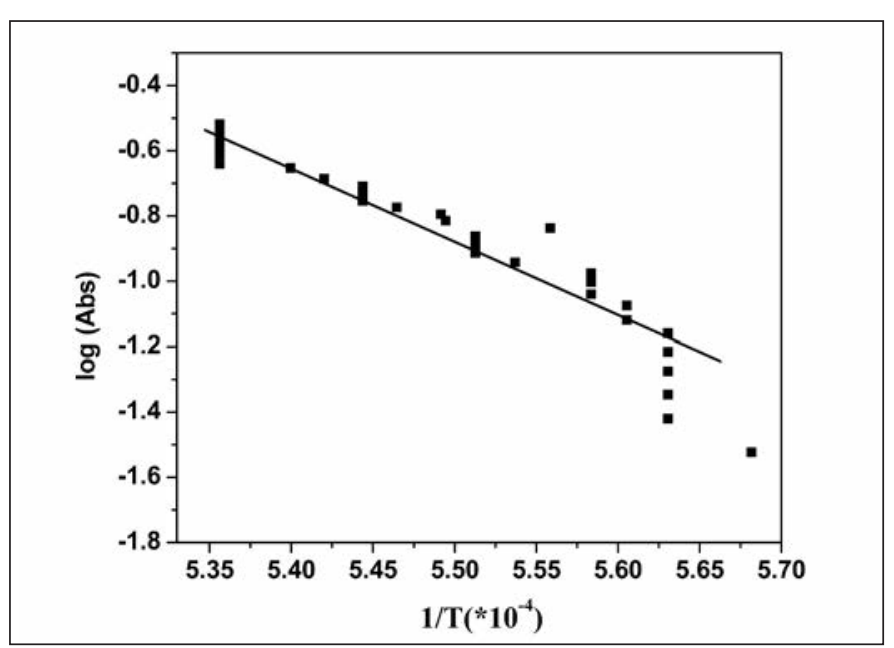

Fig. 5. Arrbenius plot for manganese in aqueous solution.

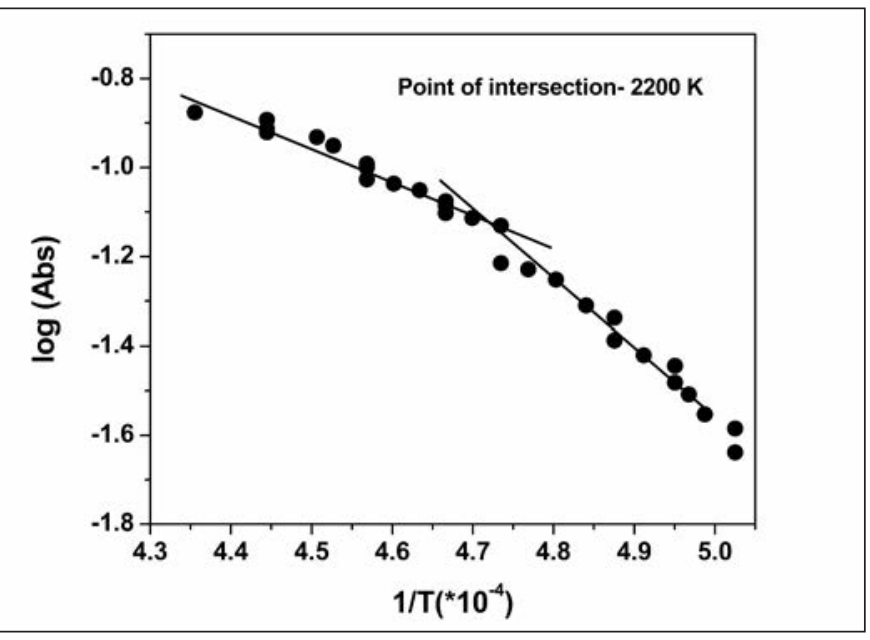

Fig. 6. Arrhenius plot for nickel in aqueous solution. 
The reported data by Sturgeon of $102 \mathrm{kcal} / \mathrm{mol}$ and $55 \mathrm{kcal} / \mathrm{mol}$ (20) and Gaydon of $54.5 \mathrm{kcal} / \mathrm{mol}$ (23) support the evaluation of our study.

It may also be noted that $\mathrm{NiO}_{(\mathrm{g})}$ $613 \mathrm{~K} \rightarrow \mathrm{Ni}_{(\mathrm{g})}$ and $\mathrm{Ni}_{(\mathrm{s} / \mathrm{l})} \rightarrow \mathrm{Ni}_{(\mathrm{g})}$ have nearly the same $E_{a}$ values. It is not easily possible to identify the unique pathway of atomization from $\mathrm{E}_{\mathrm{a}}$ value alone. However, consideration of the feasibility of carbothermic reduction and the relative value of melting point and $\mathrm{T}_{\text {app }}$ serve as pointer to suggest that $\mathrm{Ni}_{(\mathrm{s} / \mathrm{l})} \rightarrow \mathrm{Ni}_{(\mathrm{g})}$ takes place at lower temperature regions and dissociation of $\mathrm{Ni}_{2(\mathrm{~g})}$ at higher temperature regions.

The activation energies for $\mathrm{Ni}$ in uranium and thorium matrices are found nearly the same as in pure nitrate solutions. However, the appearance temperatures are higher by $200 \mathrm{~K}$ in the presence of uranium.

\section{Zinc}

The Arrhenius graph for atomization of $\mathrm{Zn}$ shows a single straight line segment (Figure 7). The slope corresponds to the atomization energy of $81+3 \mathrm{kcal} / \mathrm{mole}$. The thermogravimetric analysis of $\mathrm{Zn}$ $\left(\mathrm{NO}_{3}\right)_{2}$ by Duval (21) shows that its monoxide is formed below the $\mathrm{T}_{\text {app }}(1140 \mathrm{~K})$.
Reduction of the oxide by carbon is unfavorable below the $\mathrm{T}_{\mathrm{app}}$ as reported by Sturgeon et al. (20). The dissociation of the oxide upon vaporization to $\mathrm{Zn}_{(\mathrm{g})}$ is the major species in equilibrium with $\mathrm{ZnO}_{(\mathrm{s})}$. It was also supported by Chang et al. (28) that at the $T_{\text {app }}$, the carbothermic reduction of $\mathrm{ZnO}_{(\mathrm{s})}$ might take place even though the $\Delta G^{\circ}$ for the process was reported to be positive at $1200 \mathrm{~K}$. Reduction of the oxide by carbon is unfavorable below the $\mathrm{T}_{\mathrm{app}}$. $\mathrm{Zn}_{\mathrm{g})}$ must, therefore, result from the dissociation of $\mathrm{ZnO}_{(\mathrm{s})}$. If we agree with regard to the carbothermic reduction, then the $\mathrm{Zn}_{(\mathrm{g})}$ atoms formation must occur due either to sublimation of $\mathrm{Zn}_{(\mathrm{s})}$ or vaporization of $\mathrm{Zn}_{(\mathrm{l})}$. In either case, the $\mathrm{E}_{\mathrm{a}}$ value should be around $\pm 30 \mathrm{kcal} / \mathrm{mol}$.

$\mathrm{Zn}_{(\mathrm{g})}$ must, therefore, result from the dissociation of $\mathrm{ZnO}_{(\mathrm{s})}$. Dissociation of the oxide upon vaporization to $\mathrm{Zn}_{(\mathrm{g})}$ is the major species in equilibrium with $\mathrm{ZnO}_{(\mathrm{s} / \mathrm{g})}$. The value of the activation energy of $81 \pm 3$ $\mathrm{kcal} /$ mole for the nitrate solution is in close agreement with the bond dissociation energy of $\mathrm{ZnO}_{(\mathrm{g})}(83$ $\mathrm{kcal} /$ mole) (22). Therefore, the most probable reaction sequence of atom formation appears to be:

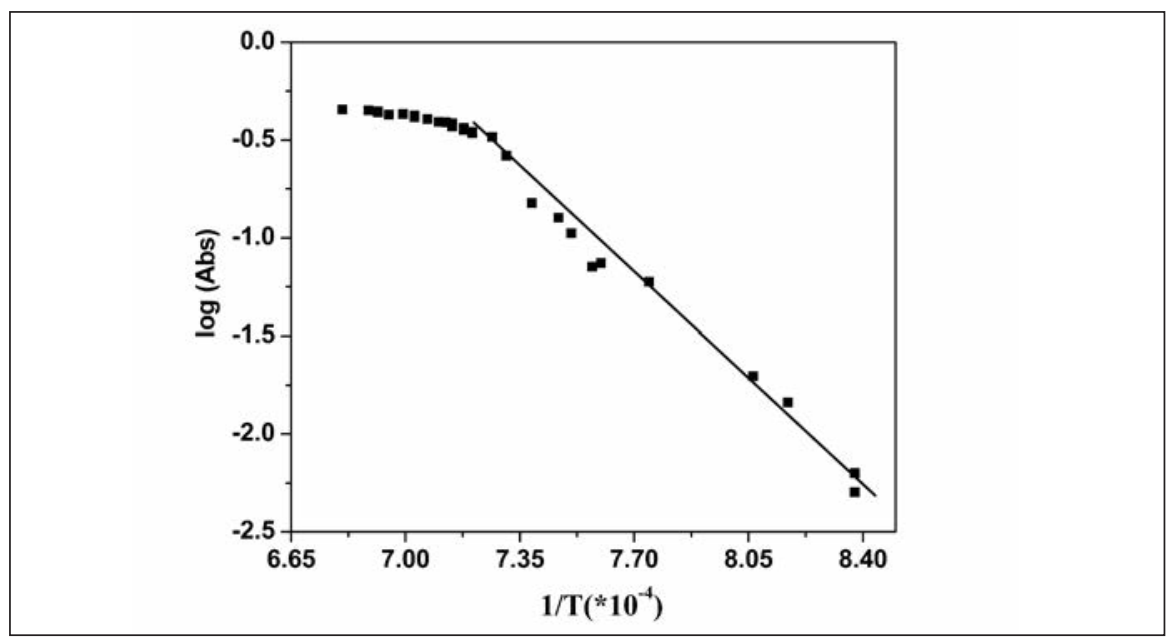

Fig. 7. Arrbenius plot for zinc in aqueous solution.

Eq. 6 $623 \mathrm{~K} \quad 1480 \mathrm{~K}$

$\mathrm{Zn}\left(\mathrm{NO}_{3}\right)_{2} \cdot 6 \mathrm{H}_{2} \mathrm{O}_{(\mathrm{s})} \rightarrow \mathrm{ZnO}_{(\mathrm{s})} \rightarrow \mathrm{ZnO}_{(\mathrm{g})} \rightarrow \mathrm{Zn}_{(\mathrm{g})}$

Before concluding that this is the most likely sequence for the atom formation of zinc, consider the following:

(a) The reported (22) melting point of $\mathrm{ZnO}_{(\mathrm{s})}$ is $2512 \mathrm{~K}$, which is much higher than the $\mathrm{T}_{\mathrm{app}}$, and means that $\mathrm{ZnO}_{(\mathrm{s})}$ is subliming to $\mathrm{ZnO}_{(\mathrm{g})}$.

(b) The CRA conditions are highly conducive for the reduction process; yet the carbothermic reduction does not play any role.

The activation energies for $\mathrm{Zn}$ in uranium and thorium matrices are found nearly the same as in pure nitrate solutions. However, the appearance temperatures are $160 \mathrm{~K}$ higher in the presence of uranium and $200 \mathrm{~K}$ higher in the presence of thorium matrix.

\section{Matrix Effect}

The atomization efficiency for the analytes under investigation is significantly lower in the presence of $100 \mu \mathrm{g}$ uranium or thorium matrices. In spite of the higher atomization temperature, the suppression in absorbance signal persists in the presence of the matrices. The reduction in atom density may also be attributed to the surface activity of the graphite atomizer as reported earlier by Rogulskii et al. (32). Therefore, studies regarding surface morphology were carried out using Scanning Electron Microscopy (SEM) for surface studies for the products formed on atomization.

\section{Scanning Electron Microscopy (SEM)}

The changes in morphology of differently treated graphite atomizers used for U/Th matrices were studied using SEM which provides information on the physical state of the atomizer surface. SEM images 


\section{Atomic}

of the cross-section of a fresh atomizer, high temperature heated atomizer with $0.1 \mathrm{M} \mathrm{HNO}_{3}$, and an atomizer treated with $\mathrm{U}$ and $\mathrm{Th}$ matrices were obtained by SEM and are shown in Figure 8 (a-e). Figure 8(a) shows the surface of an atomizer without any treatment, while Figure $8(\mathrm{~b}-\mathrm{e})$ shows the tube surface after 40 atomization cycles on loading with $0.1 \mathrm{M} \mathrm{HNO}_{3}$ (b), uranyl nitrate $(\mathrm{c}, \mathrm{d})$, and thorium nitrate (e). The SEM images revealed that the surfaces observed before treatment and after treatment with $0.1 \mathrm{M} \mathrm{HNO}_{3}$ were almost similar to the new atomizer with slight roughening of the surface. In case of the $\mathrm{U}$ - and Th-treated atomizers, the original grain structure was destroyed and numerous small pits and pores were observed. These pits and pores may be produced on the surface of the atomizer due to interaction of the matrix with the graphite, leading to erosion of the layer.

A globule-like structure (protrusion) observed in uranium (Figure $8 d$ ) is probably due to the partial dissolution of $\mathrm{UC} / \mathrm{UC}_{2}$ and re-formation of the uranium carbide layer during repeated loading of the sample aliquot. Presence of $\mathrm{UO}_{2}$ at $2700{ }^{\circ} \mathrm{C}$ also confirms re-dissolution of $\mathrm{UC}_{2}$ in the next aliquot loaded. This type of $\mathrm{UO}_{2}$ dissolution on the atomizer was also reported by Hircq (33). The roughening of the surface leads to suppression in absorbance in the presence of uranium.

The suppression in absorbance was observed right from the first atomization of the new atomizer as well; and where there is no surface erosion, it can be assumed that suppression in the absorbance signal due to the atomizer deterioration cannot be the only cause.

The SEM image of the Th-treated atomizer (Figure 8e) is representative of a highly corrosive effect of Th with numerous pores and pits on the surface. No globule-like structure (protrusion) of thorium could be seen since dissolution of thoria essentially requires $\mathrm{HF}$ along with $\mathrm{HNO}_{3}$. Hence, $\mathrm{ThC}_{2}$ did not dissolve in $\mathrm{HNO}_{3}$ during the next aliquot loading.
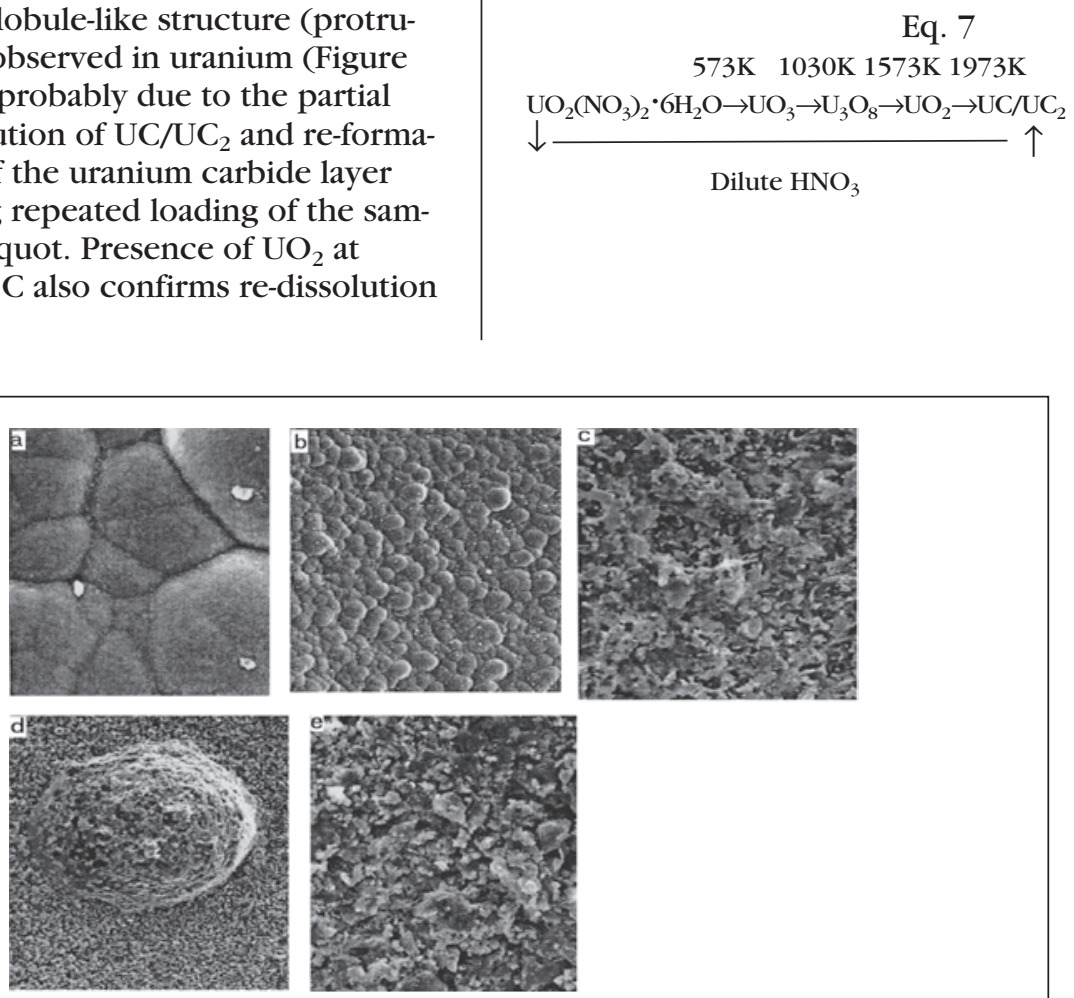

Fig. 8. SEM micrographs of the atomizer tubes: (a) without treatment, (b) $0.1 \mathrm{M}$ $\mathrm{HNO}_{3}$, (c) uranyl nitrate, (d) uranyl nitrate globule, and (e) thorium nitrate.
Eq. 8
$\mathrm{Th}\left(\mathrm{NO}_{3}\right)_{4} \cdot 6 \mathrm{H}_{2} \mathrm{O}_{(\mathrm{s})} \rightarrow \mathrm{ThO}_{2(\mathrm{~s})} \rightarrow \mathrm{ThC}_{2}$

These SEM data clearly show the formation of stable oxide/carbide lattices. These lattices are formed on the surface at a temperature of $1500 \mathrm{~K}$ and both uranium and thorium nitrates get converted into their respective dioxides (4). Similarly, the analytes get converted into their oxides, mostly dissolved in the main lattice of $(\mathrm{Th} / \mathrm{U}) \mathrm{O}_{2} / \mathrm{C}$. The diffusion rates of cationic elements in these lattices are very low. Thoria and urania lattices are very stable and have a defect-free structure due to their stoichiometric composition. Moreover, a fraction of the analytes dissolved in the ( Th/U) $\mathrm{O}_{2} / \mathrm{C}$ lattice, but considerably reduced their chemical activities, hence, their detectability. This is mainly due to the fact that nanogram amounts of analytes are being atomized in the presence of milligram amounts of uranium and thorium matrices.

The results of SEM showed that surface erosion occurred in the presence of $\mathrm{U} / \mathrm{Th}$ matrices. This is mainly due to the carbonization reaction occurring on the surface. The observed changes in the $\mathrm{T}_{\mathrm{app}}$ could not be directly correlated with the changes on the surface.

The observed changes in the $\mathrm{T}_{\text {app }}$ are explained with the help of absorbance vs. time profiles. Peak profiles for $\mathrm{Cu}, \mathrm{Cr}, \mathrm{Mn}, \mathrm{Ni}$, and $\mathrm{Zn}$ were plotted with and without uranium/thorium matrices. The three graphs within Figure 9 (a,b,c,d,e) represent 0 (matrix-free), $20 \mathrm{mg} / \mathrm{mL}$ $\mathrm{U}$, and $20 \mathrm{mg} / \mathrm{mL}$ Th matrix concentrations for each of the elements.

It can be seen from the graphs that the peak profiles broaden and peak height reduces with the matrix as compared to the matrixfree solution. A large suppression in peak absorbance profile is seen with the matrix concentration. The 
absorbance suppression in the analytes at $20 \mathrm{mg} / \mathrm{mL}$ is $~ 50 \%$ for almost all of the elements as compared to the matrix-free solution. It is also clear from the plots that the appearance of the signal is delayed as well as the peak height. The suppression in the signal is due to the delay in appearance signal and peak signal.

\section{CONCLUSION}

In this study, we have tried to understand the reason behind the suppression of analyte absorbance in the presence of uranium and thorium matrices. The mode of atomization remained the same irrespective of the matrices, therefore, studies regarding surface morphol- ogy were carried out using Scanning Electron Microscopy (SEM). The changes in morphology of differently treated graphite atomizers used for U/Th matrices were found to be different. The results of SEM showed that surface erosion occurred in the presence of U/Th matrices. The SEM image of the Thtreated atomizer is representative of a highly corrosive effect of Th with lots of pores and pits on the surface and, hence, suppression in the analyte absorbance is more in the Th matrix. While a globulelike structure (protrusion) was observed in uranium, this is probably due to the partial dissolution of $\mathrm{UC} / \mathrm{UC}_{2}$ and re-formation of the uranium carbide layer during repeated loading of the sample aliquot.
It can be concluded that the mode of atomization remains essentially constant irrespective of the type of matrices present. Reduction in the absorbance signal can be due to the slowing down of the reaction kinetics in the atomization process with a high concentration of matrix. Analytes are in nanograms, while the matrix is in milligram amounts. Formation of stable matrix carbides on the inner surface of the atomizer blocks the analyte atoms and suppresses the atom density of the analytes. Surface roughening can markedly affect evaporation of the solution and will also lead to suppression in absorbance.

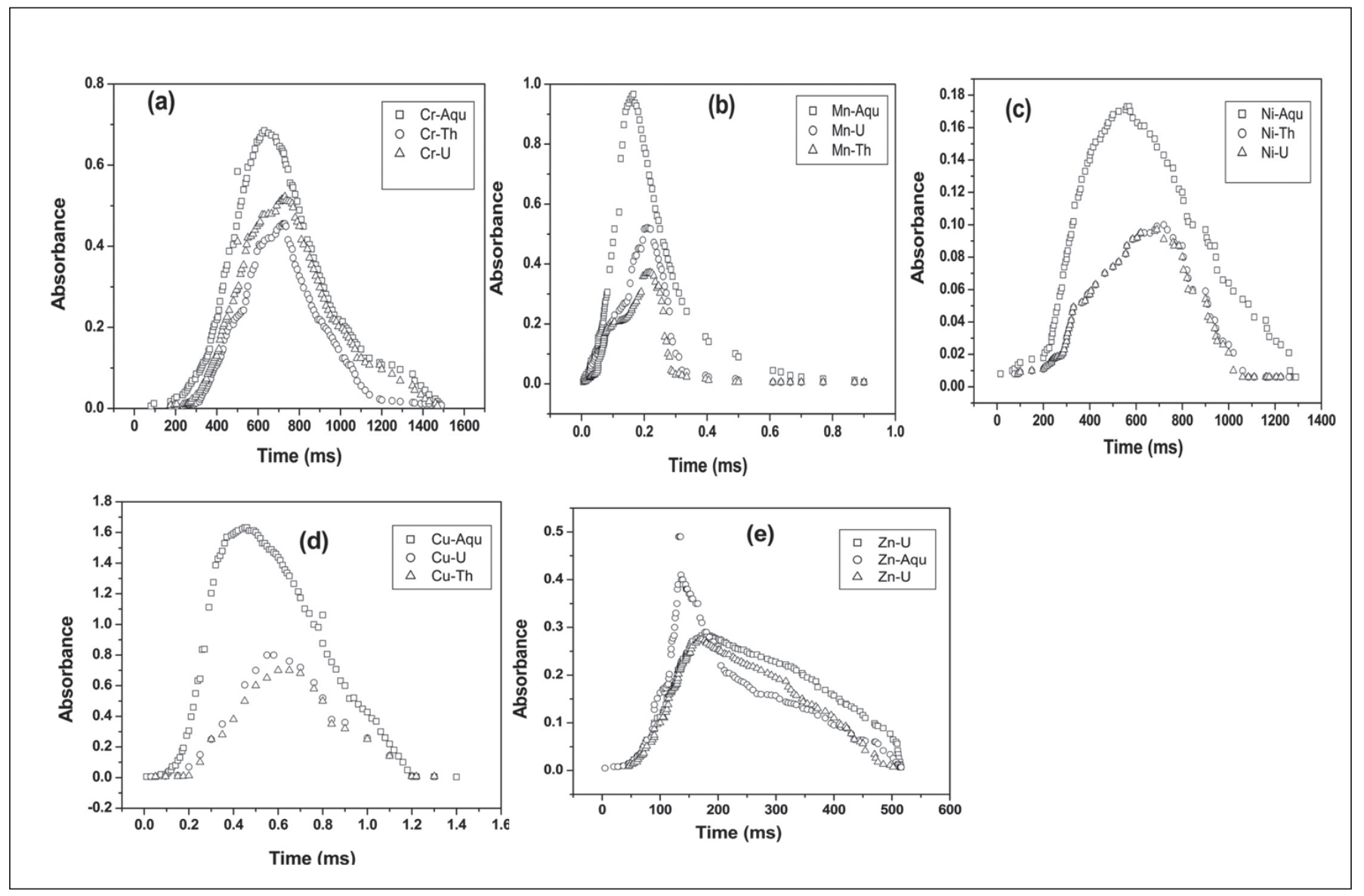

Fig. $9(a, b, c, d, e)$. Absorbance vs. time profiles for the Cu, Cr, Mn, Ni, and Zn transition metals in aqueous, uranium, and thorium matrices. 


\section{ACKNOWLEDGMENT}

The authors are grateful to Dr. Ashok Goswami, Head, Radiochemistry Division, for his keen interest and constant encouragement in the course of this work. The authors express their sincere thanks to Dr. D.N. Saha and Mr. S.M. Sathe, Radiometallurgy Division, BARC, for providing their help in the SEM images for the samples.

\section{REFERENCES}

1. S. K. Gupta, S.K. Thulasidas, Neelam Goyal, and S.V. Godbole, At. Spectrosc. 34, 104 (2013).

2. S. K. Gupta, Neelam Goyal, and S.V. Godbole, At. Spectrosc. 32, 107 (2011).

3. Neelam Goyal, P.J. Purohit, and S.V. Godbole, At. Spectrosc. 31, 190 (2010).

4. Neelam Goyal, P.J. Purohit, S.K. Gupta, and S.V. Godbole, At. Spectrosc. 32, 206 (2011).

Received July 22, 2013.

\section{Atomic Spectroscopy \\ 1 Vol. 34(6), Nov./Dec. 2013}

18. R.E. Sturgeon, C.L. Chakrabarti, C.H. Langford. Anal. Chem. 48, 1792, (1976).

19. M.D. Sastry, M.K. Bhide, K. Savitri, Y. Babu, and B.D. Joshi,, F.Z. Anal. Chem. 298, 367 (1978).

20. R.E. Sturgeon, Prog. Anal. At. Spectrosc. 1, 148 (1978).

21. C. Duval, Inorganic Thermodynamic Analysis, 2nd Edition, Elsevier, New York, 1963

22. R.C. Weast, CRC Handbook of Chemistry and Physics, 55th Edition. Chemical Rubber Company. OH, USA. (1975).

23. A.G. Gaydon, Dissociation Energies and Spectra of Diatomic Molecule, 3nd Edition, Chapman and Hall Ltd., London, UK (1968).

24. O. Genc, S. Akman, A.R. Özdural, S. Ateş, and T. Balkis. Spectrochim. Acta B, 36, 163 (1981).

25. J. R. Castillo, J. M. Mir, and C. Bendicho, Spectrochim. Acta, Part B, 436, 263 (1988). Page, J. Anal. At. Spectrom. 2, 459 (1987).

9. B.M. Patel, P.M. Bhatt, Neelam Gupta, M.M. Pawar, and B.D. Joshi, Anal. Chim. Acta.104, 113 (1979)

10. B.M. Patel, Neelam Gupta, P.J. Purohit, and B.D. Joshi, Anal. Chim. Acta 118, 163 (1980).

11. B. M. Patel, Neelam Gupta, P.J. Purohit, A.R. Dhobale, and B.D. Joshi. F.Z. Anal. Chem. 315, 42 (1983).

12. Neelam Goyal, M.J. Kulkarni, S.K. Thulasidas, P.J. Purohit, and A.G. Page, Anal. Lett. 32, 3059 (1999).

13. Neelam Goyal, P.J. Purohit, M.J. Kulkarni, and S.V. Godbole, At. Spectrosc. 30, 156 (2009).

14. R.K. Sinha and A. Kakodkar, Nucl. Eng. Des. 236, 683 (2006).

15. W.C. Campbell and J.M. Ottaway, Talanta 21, 837 (1974).

16. R.E. Sturgeon, C.L. Chakrabarti, and P.C. Bertels, Anal. Chem. 47, 1250 (1975).

17. R E. Sturgeon, C.L. Chakrabarti, I.S. Maines, and P.C. Bertels, Anal. Chem. 47, 1240 (1975).
26. B.V. L'vov, Spectrochim. Acta, Part B, 52, 1 (1997).

27. J. Aggett and A.J. Sprott, Anal. Chim. Acta 72, 49 (1974).

28. S.B. Chang and C.L. Chakrabarti, Anal. At. Spectrosc. 8, 83, (1985).

29. A. Kant, J. Chem. Phys. 41,1872 (1964).

30. M.D. Morse, J. Chem. Rev. 86, 1 049 (1986)

31. L. Brewer and D.F. Mastick, J. Chem. Phys. 19, 834 (1951).

32. Y.V. Rogulskii, A.N. Bugai, and A.N. Kulik, J. Appl. Spectrosc. 71, 282 (2004).

33. B. Hircq, Spectrochim. Acta, Part B, 71, 153, (1976). 